as well as in those children and adolescents who satisfy the rigid criteria of manic-depressive illness. Brumback and Weinberg ${ }^{17}$ gave $30 \mathrm{mg}$ per $\mathrm{kg}$ per day (divided into three doses) to five prepubertal children with manic episodes, and this easily maintained therapeutic blood concentrations between 0.6 and $1.5 \mathrm{mmol}(\mathrm{mEq}) / 1$. But this is a very large dose. A sound procedure is to start with a much lower dose, which is often clinically effective, ${ }^{11}$ and modify it if necessary according to the child's response; but-unless toxic reactions developtreatment should not be abandoned until therapeutic blood concentrations have been maintained for at least two weeks without improvement.

${ }^{1}$ Campbell, J D, fournal of Nervous and Mental Diseases, 1952, 116, 424.

2 Campbell, J D, fournal of the American Medical Association, 1955, 158, 154

${ }^{3}$ Annell, A L, ed, Depressive States in Childhood and Adolescence. Almquist and Wiksell, 1972 .

4 Weinberg, W A, et al, fournal of Pediatrics, 1973, 83, 1065.

5 Stack, J, in Depressive States in Childhood and Adolescence, Proceedings of the 4th UEP Congress, Stockholm 1971, p 460. Almqvist and Wiksell, 1972.

${ }^{6}$ Bauersfeld, $\mathrm{K} \mathrm{H}$, in Depressive States in Childhood and Adolescence, p 281. Almqvist and Wiksell, 1972.

'MacAuslan, A, Child: Care Health and Development, 1975, 1, 225.

${ }^{8}$ McKnew, D H, Cytryn, L, and White, I, fournal of the American Academy of Child Psychiatry, 1974, 13, 576.

${ }^{9}$ Shopsin, B, and Gershon, S, American fournal of the Medical Sciences, $1974,268,306$.

${ }^{10}$ Horowitz, H A, Diseases of the Nervous System, 1977, 38, 480.

11 Frommer, E A, in Recent Developments in Affective Disorders, eds A Coppen and A Walk, p 117. London, British Journal of Psychiatry Special Publication No 2, 1968.

12 Annell, A L, Acta Psychiatrica Scandinavica, 1969, Suppl 207, 19.

13 Annell, A L, Acta Paedopsychiatrica, 1969, 36, 292.

${ }^{14}$ Anthony, J, and Scott, P, Fournal of Child Psychology and Psychiatry and Allied Disciplines, 1960, 1, 53.

${ }^{15}$ Feinstein, S C, and Wolpert, E A, fournal of the American Academy of Child Psychiatry, 1973, 12, 123.

16 Weinberg, W A, and Brumback, R A, American fournal of Diseases of Children, 1976, 130, 380.

17 Brumback, R A, and Weinberg, W A, American fournal of Diseases of Children, 1977, 131, 1122.

18 Youngerman, J, and Canino, I, Archives of General Psychiatry, 1978, 35, 216.

19 Schou, M, Amdisen, A, and Baastrup, P C, British fournal of Hospital Medicine, 1971, 6, 53.

\section{Registers for the prevention of genetic disease}

Following a recommendation by the World Health Organisation $^{1}$ a working party of the Clinical Genetic Society has now proposed $^{2}$ that preventive genetic registers should be used in Britain to reduce the transmission of inherited disease. This report scrupulously explores the implications of such registers and deserves careful study-because the prospect of genetic registers may alarm some people. In fact, registers of various sorts have been in operation for many years without causing much concern. Hospital diagnostic indexes, lists of "teaching patients," and registers of rare disorders such as haemophilia, polyposis coli, or phenylketonuria have been widely accepted, while registers for the prevention of genetic disease have already been set up in several parts of the world-for example, in Edinburgh, Belgium, and the United States ${ }^{3}$-without excessive difficulty.

Preventive genetic registers appear to be novel because they identify people who are healthy but who risk transmitting inherited disorders to their children. Even this concept is not entirely new: public health authorities have long had the responsibility for seeking out apparently healthy contacts of patients with tuberculosis, typhoid, venereal disease, and other infections. Nevertheless, what might be acceptable in other specialties becomes suspect where genetic disorders are concerned, because of the totalitarian excesses of the twentieth century, and we would all be apprehensive about authoritarian intervention in this area.

To see how a preventive genetic register might work let us consider Duchenne muscular dystrophy. The first step would be to identify all known cases. Next blood tests could be offered to appropriate female relatives. The results of these tests, together with pedigrees and complicated statistics, would allow most carriers to be identified. When pregnant, carriers could then be offered prenatal fetal sexing and abortion of male fetuses. These procedures are available and to some extent already routine even without genetic registers. There are, however, still some uncertainties about the accuracy of carrier detection and the morality of aborting males, half of whom would be normal, while allowing the survival of females, half of whom would be carriers. These reservations make it essential that the parents concerned should always be fully informed and that each stage-inclusion in a register, carrier detection, prenatal diagnosis, and terminationshould be wholly voluntary. A Duchenne register of this kind is not a eugenic measure: though the prevalence of affected boys might be greatly reduced the numbers of carriers would probably increase-as would the frequency of the gene in the population. The gain from the existence of a register would be the avoidance of the agony for all concerned in watching affected boys slowly die of an untreatable disease-and it would almost certainly save money, too.

What other diseases would be included in a genetic register? In theory, ${ }^{4}$ the autosomal dominant and X-linked recessive disorders offer the best scope for prevention, and this has been confirmed by follow-up of individuals referred for genetic counselling. ${ }^{5}$ A preventive register should include particularly those diseases in which some positive benefit may follow-for example, carrier detection or prenatal diagnosis, as in Duchenne muscular dystrophy, haemophilia, and polyposis coli. Individuals with balanced chromosome translocations could also be helped by the prenatal detection of chromosomally unbalanced fetuses. There are even some autosomal recessive disorders (admittedly rare) such as Tay Sachs disease in which carriers can be detected and affected fetuses aborted; within groups of people where these diseases ate common a register would have considerable advantages. Huntington's chorea has probably become more clearly associated with genetic registers than any other disorder. Some progress has been made in our understanding of this dreadful disease, ${ }^{6}$ but we still cannot identify symptomless heterozygotes or treat choreics. Furthermore, some heterozygotes may take no notice of genetic counselling: they tend to be defiant towards the disorder, often refusing to let it interfere with their lives or their procreation. In these circumstances, the inclusion of Huntington's chorea in a preventive genetic register would be unlikely to achieve very much. Research in Huntington's chorea must go on, but until a diagnostic or therapeutic breakthrough occurs registers are best maintained by specialised units on a research rather than a service basis.

While clinical geneticists are familiar with registers for preventing inherited disease, whether the medical profession as a whole and their patients will accept them will depend on their image. If registers are seen to be part of diagnosis and support they are likely to be accepted. On the other hand, a government-run, national, multiaccess computer register for the prevention of genetic disease would probably be unacceptable, and the working party of the Clinical Genetics Society has 
wisely recommended that only a small, dedicated minicomputer (an electronic card index) should be used, which should be locked up within the clinical genetics department. This should guarantee considerably greater confidentiality than that provided by most open hospital and family doctor records, though safeguards must also be built in to guarantee future confidentiality.

Support for affected families is of great importance. If we are to bring distressing information to the attention of relatives then we must give them whatever support is necessary. Genetic counselling should be a humane and cost-effective way of preventing intractable disease, but so far only a few of those who could benefit have actually received counselling. ${ }^{7}$ An expanded counselling team including the family doctor and supported by a genetic register could go a long way towards closing that gap. We are all carriers of an assortment of lethal recessive disorders, so logically no stigma should attach to the inclusion of our names in a register. Recent advances, notably in the analysis of HLA types, have shown that we all have markers of disease susceptibility. Before long, registration of these markers at an early age may allow prospective screening and early treatment for many more conditions.

${ }^{1}$ World Health Organisation, Report of a Scientific Group. Genetic Disorders: Prevention, Treatment, and Rehabilitation. Technical Report Series No 497. Geneva, World Health Organisation, 1972

${ }^{2}$ Emery, A E H, et al, fournal of Medical Genetics, 1978, 15, in press.

${ }^{3}$ Registers for the Detection and Prevention of Genetic Disease, Proceedings of a Workshop held in Albany, New York, October 13, 1975, ed A E H Emery and J R Muller. New York, Stratton Intercontinental, 1976.

${ }^{4}$ Smith, C, in Modern Trends in Human Genetics, vol 1, ed A E H Emery, p 350 . London, Butterworths, 1970.

${ }^{5}$ Emery, A E H, and Smith, C, British Medical fournal, 1970, 3, 636.

${ }^{6}$ British Medical fournal, 1978, 1, 528.

${ }^{7}$ Emery, A E H, British Medical fournal, 1975, 3, 219.

\section{Pathogenesis of amyloid disease}

Though it may be localised, amyloid disease is usually widely distributed in the body. Generalised amyloidosis is classically divided into primary and secondary types. Whereas primary amyloidosis arises idiopathically or as a complication of multiple myeloma, secondary amyloidosis follows some morbid condition other than multiple myeloma. This may be a chronic suppurative condition, caseous tuberculosis, or tertiary syphilis; more common current causes are lepromatous leprosy, ${ }^{1}$ rheumatoid arthritis, the decubitus ulceration and suppurative pyelonephritis that complicate longstanding paraplegia, ${ }^{2}$ and cancer (especially Hodgkin's disease and renal carcinoma). Nevertheless, amyloidosis is an uncommon complication of all these diseases. Even in multiple myeloma primary amyloidosis occurs in only $10 \%$ of cases.

Amyloid is protein with a characteristic fibrillar structure on electron microscopy; it is an eosinophilic, hyaline material, and may be deposited in various organs. It is not, however, a single protein. The amyloid of primary amyloidosis consists of the light chains (or part of them) of immunoglobulin; Bence-Jones protein, which consists of the light chains of an immunoglobulin produced by myeloma cells, gives rise to fibres of identical appearance and staining properties on limited peptic digestion. But the amyloid of secondary amyloidosis-called amyloid A (AA) protein-has a quite different amino-acid sequence and is of unknown origin. In fact, amyloid fibrils can probably be formed from different polypeptide fragments, derived from either immunoglobulin or some other protein; in vitro many proteins-for example, insulin, glucagon, and calcitonin-yield products on peptic digestion that form typical amyloid fibrils. Possibly in a chronic destructive disease such as osteomyelitis the tissue proteins themselves provide the raw material. At all events serum AA (SAA), which seems to be a circulating precursor of amyloid fibrils, occurs not only in all cases of secondary amyloidosis and in some chronic diseases (such as rheumatoid arthritis, tuberculosis, and cancer) but also in all normal adults-in a low concentration that increases with age. In generalised amyloidosis the precursor of amyloid fibrils can thus be either SAA or immunoglobulin circulating in the blood stream to be deposited in the tissues.

Another approach has been proposed recently by Scheinberg and Cathcart. They argue that primary and secondary amyloidosis are both disturbances of immune regulation, with excessive production of B lymphocytes, and from work in mice they suggest a mechanism implicating both $T$ and $B$ lymphocytes and macrophages. ${ }^{8}$ Mice develop the secondary type of disease when given large doses of casein (used as an analogue of any tissue breakdown products), and sometimes show the primary type after being inoculated with plasma cell tumours. In such mice the function of $\mathrm{T}$ lymphocytes is suppressed and that of B lymphocytes enhanced. ${ }^{910}$ The initial event in both types of amyloidosis, Scheinberg and Cathcart suggest, is activation of macrophages, which secrete substances that stimulate B lymphocytes and suppress $T$ lymphocytes. The latter normally control the activity and proliferation of macrophages and B lymphocytes. Intensive short-term antigenic stimulation of the reticuloendothelial system, which occurs in mice treated with casein, might lead to the rapid accumulation and laying down of AA protein in the connective tissue, and also account for the considerable proliferation of B cells (immunoblasts) and the non-specific suppression of $\mathrm{T}$ cells. On the other hand, more sustained but less intensive activation of macrophages could give rise to the proliferation of a single clone of mature plasma cells and deposition of immunoglobulin light-chain material in the form of fibrils of the primary type of amyloid.

This is an interesting hypothesis, but as yet it is no more than that. Nevertheless, giving thymic hormone (thymosin) at the same time as casein prevents amyloidosis in mice, ${ }^{11}$ possibly by restoring $\mathrm{T}$ lymphocytes and their controlling function; and colchicine, which interferes with the structural organisation and function of reticuloendothelial cells, has a similar inhibiting effect when given with casein. ${ }^{12}{ }^{13}$ Whether or not the theory finally turns out to be true, a therapeutic trial of thymosin or colchicine might be worth while in patients with this obscure but fascinating malady.

\footnotetext{
${ }^{1}$ McAdam, K P W, et al, Lancet, 1975, 2, 572.

2 Tribe, C R, and Silver, J R, Renal Failure in Paraplegia, p 54. London, Pitman Medical, 1969.

${ }^{3}$ Glenner, G G, et al, Science, 1971, 174, 712.

${ }^{4}$ Isersky, C, et al, fournal of Immunology, 1972, 108, 486.

${ }^{5}$ Glenner, G G, Ein, D, and Terry, W D, American fournal of Medicine, $1972,52,141$.

${ }^{6}$ Katz, A, and Pruzanski, W, Canadian Medical Association fournal, 1976 , 114, 872 .

7 Glenner, G G, and Page, D L, International Review of Experimental Pathology, 1976, 15, 2.

8 Scheinberg, M A, and Cathcart, E S, Clinical and Experimental Immunology, 1978, 33, 185.

9 Cohen, A S, and Cathcart, E S, Methods and Achievements in Experimental Pathology, 1972, 6, 207.

10 Scheinberg, M A, and Cathcart, E S, Immunology, 1976, 31, 443.

11 Scheinberg, M A, Goldstein, A L, and Cathcart, E S, fournal of Immunology, 1976, 116, 156

12 Kedar, I, et al, Israel fournal of Medical Science, 1974, 10, 787.

13 Shirahama, T, and Cohen, A S, fournal of Experimental Medicine, 1974 $140,1102$.
} 